\title{
Research on the influence of uneven solar radiation distribution on the radiant floor heating system in railway stations on Tibetan Plateau
}

\author{
Jiacheng Zheng ${ }^{1}$, Tao $\mathrm{Yu}^{1, *}$, Bo Lei ${ }^{1}$, Ruixin $\mathrm{Lv}^{1}$, Chen $\mathrm{Chen}^{1}$ and Xiujing Luo ${ }^{1}$ \\ ${ }^{1}$ School of Mechanical Engineering, Southwest Jiaotong University, Chengdu 610031, China
}

\begin{abstract}
In cold regions, radiant floor heating systems are commonly used in public buildings due to better thermal comfort and lower energy consumption. However, in transportation buildings with many transparent envelopes such as railway stations on Tibetan Plateau, the strong solar radiation entering into the station may cause local overheating, which has a great effect on the radiant floor heating system. In this paper, a railway station on Tibetan Plateau is simulated to investigate the influence of uneven solar radiation distribution on the radiant floor heating system. Results show that due to the strong solar radiation, the floor surface temperature and indoor operative temperature in some parts of the waiting hall can reach up to $30{ }^{\circ} \mathrm{C}$ and $26^{\circ} \mathrm{C}$, respectively. The temperature difference of the floor surface can even exceed $5^{\circ} \mathrm{C}$ occasionally during the heating period. According to the results, it can be found that the method of reducing the heating in the area with strong solar radiation and making full use of solar radiation for heating is an effective way to improve the indoor thermal comfort and reduce the heating energy consumption of heating system.
\end{abstract}

\section{Introduction}

Currently, transportation buildings such as railway stations are developing very quickly in China. Compared with other buildings, high ceiling and large span without partitions are adopted in these buildings for better vision and aesthetic. In addition, for the purpose of aesthetic and better use of natural light, the envelope of such buildings usually adopts transparent materials, such as glass wall, skylight or transparent film [1].

Nowadays, because of the huge energy consumption of transportation buildings, people pay more attention to the energy saving of them. Rational use of solar energy is one of the effective ways to reduce the energy consumption of buildings, but the utilization of solar energy often depends on local conditions. Tibetan Plateau is the region with the most abundant solar energy resources in China and heating is dominant for all buildings over there due to the specific cold climate during most time of the year [2,3]. Therefore, the use of solar energy is suitable for building heating on Tibetan Plateau. In the design stage of the buildings on Tibetan Plateau, parameters including the window-wall ratio, the orientation, window details (size and location) and the proper sun shade, should be carefully considered. For example, extensive window on the southern exterior wall is the most striking feature in some buildings. In this way, enough solar radiation can be brought into the room for heating [4].

As a low temperature heating system, radiant floor heating system is widely used in transportation buildings due to its utility, energy efficiency and aesthetics [5]. Considering the characteristics of transportation buildings, as shown in Fig. 1, the strong solar radiation irradiates on part of the radiant floor surface through the transparent envelope and affects the thermal performance of the radiant floor system. In the cooling season, radiant floor system can remove the heat from the solar radiation quickly and increase the cooling performance of the system [6-8]. However, in the heating season, solar radiation can cause the local overheating in the room and reduce the heating performance of radiant floor system [9, 10]. Moreover, the solar radiation entering into the room is not fully utilized. Therefore, it is very important to understand the influence of uneven solar radiation distribution on the radiant floor heating system.

In this paper, a railway station on Tibetan Plateau is selected as the study building, the thermal model of which is built to study the influence of uneven solar radiation distribution on the radiant floor heating system by Ecotect and Energyplus software. According to the uneven solar radiation distribution, this paper divides the heating system into the $\mathrm{S}$ zone strongly influenced by solar radiation and the $\mathrm{W}$ zone weakly influenced by solar radiation. Both the indoor temperature and the energy use of the radiant floor system between the $\mathrm{S}$ zone and $\mathrm{W}$ zone are compared.

* Corresponding author: yutao073@swjtu.edu.cn 


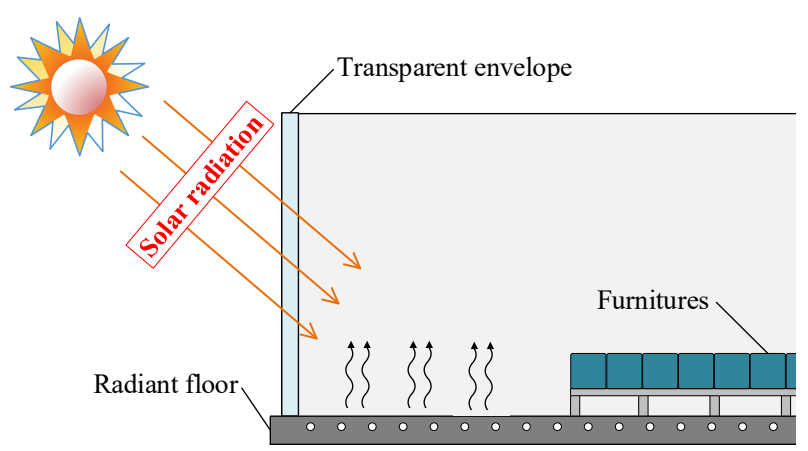

Fig. 1. Solar radiation entering into the room.

\section{Simulated model}

In order to study the influence of uneven solar radiation distribution on the radiant floor system, a simulation on a railway station on Tibetan Plateau is carried out. In this building, the distribution of solar radiation is very important and is simulated by Ecotect software firstly. Then, according to the uneven solar radiation distribution, the radiant floor system is divided into two zones. Finally, Energyplus software is used to analyze the indoor thermal environment in this railway station and the heating needs of the radiant floor system.

\subsection{Studied building}

The building studied is a typical railway station facing south, located in Lhasa of Tibet, China. It has two floors, and the floor plan of each floor is shown in Fig. 2. In this building, the waiting hall is the focus of this study and the size is $126.0 \mathrm{~m}$ (length) $\times 46.0 \mathrm{~m}$ (width). The heights of the two floors are $8.4 \mathrm{~m}$ and $8.7 \mathrm{~m}$, respectively. On the south and north exterior walls, there are some glass walls and the total window-wall ratio is about 0.57 .

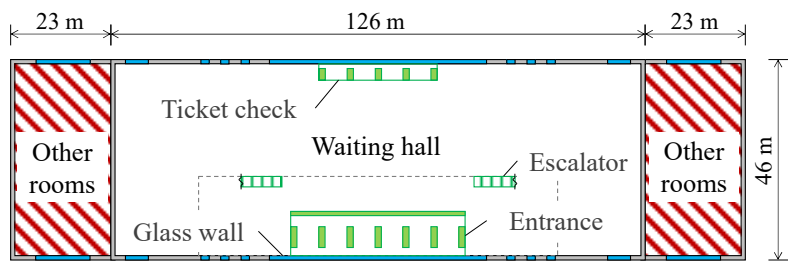

(1) North

(a) $1 \mathrm{~F}$

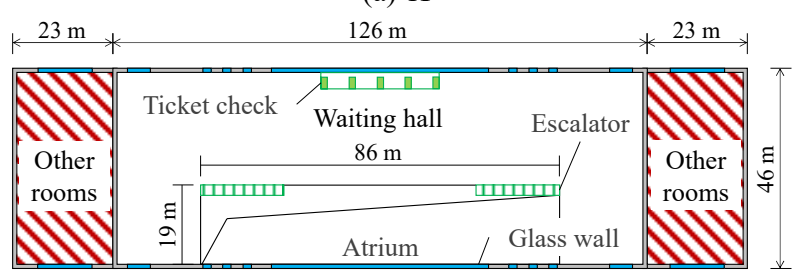

(4) North

(b) $2 \mathrm{~F}$

Fig. 2. Floor plans of the studied railway station.

Based on the building standards in Lhasa (cold regions), some heat transfer coefficients of the building constructions given in the model are listed in Table 1 [11]. Furthermore, the SHGC (Solar Heat Gain Coefficient) of glass walls in the model is 0.72 [12].

Table 1. Heat transfer coefficients of the building constructions.

\begin{tabular}{cc}
\hline Building Construction & $\begin{array}{c}\text { Heat Transfer Coefficient } \\
\left(\mathbf{W} / \mathbf{m}^{2} \cdot \mathbf{K}\right)\end{array}$ \\
\hline Exterior Wall & 0.50 \\
Interior Wall & 1.30 \\
Exterior Roof & 0.45 \\
Exterior Floor & 0.50 \\
Interior Ceiling/Floor & 1.00 \\
Glass wall & 2.00 \\
\hline
\end{tabular}

\subsection{Solar radiation distribution}

Ecotect software is used to simulate the solar radiation distribution on the floor surfaces of the waiting hall. In this software, meteorological parameters in Lhasa are used and the simulated period is the heating season from November 15 to March 15 of the following year (a total of 121 days). The simulation results of the solar radiation distribution on the 1st and 2nd floor surfaces of the waiting hall are shown in Fig. 3.

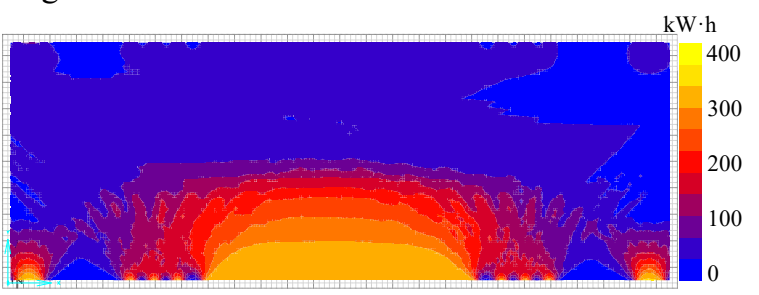

(a) $1 \mathrm{~F}$

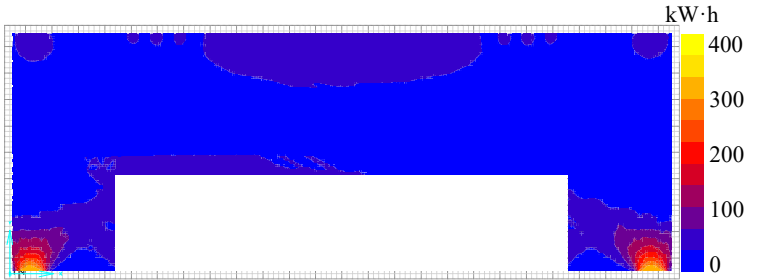

(b) $2 \mathrm{~F}$

Fig. 3. Cumulative solar radiation on the floor surface of waiting hall.

It can be seen from the results that the solar radiation irradiating on the floor surface in the 1 st floor is significantly different from the south to the north. The zone near the southern exterior wall is largely affected by the solar radiation than the other zones. In this study, the 1 st floor of the waiting hall is evenly divided into the $S$ zone strongly influenced by solar radiation and the $\mathrm{W}$ zone weakly influenced by solar radiation. As shown in Fig. 4, each zone occupies half of the entire waiting hall area.

Through the analysis of the simulated data, it can be found that the average cumulative solar radiation on the floor surface in the $\mathrm{S}$ zone during the heating season is $161.6 \mathrm{kWh}$. However, this value in the $\mathrm{W}$ zone is 48.8 $\mathrm{kWh}$, which is only $30.2 \%$ of that in the $\mathrm{S}$ zone.

In addition, the solar radiation distribution of the 2 nd floor in the waiting hall is obviously different from that of the 1 st floor. Because of the presence of the atrium zone, the floor surface of the 2nd floor is irradiated by solar radiation more evenly. Therefore, there is no need to 
divide the 2nd floor into $\mathrm{S}$ zone and $\mathrm{W}$ zone as the 1 st floor.

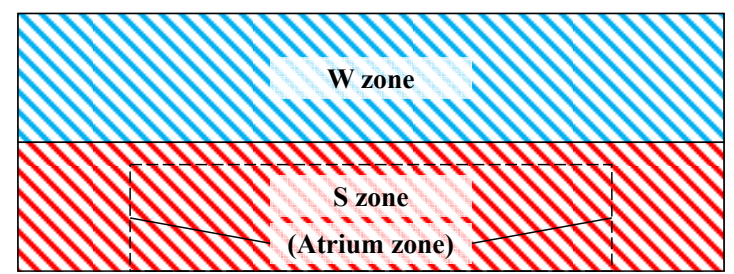

Fig. 4. $\mathrm{S}$ zone and $\mathrm{W}$ zone in the 1 st floor of the waiting hall.

\subsection{HVAC system}

In order to analyze the indoor thermal environment and the heating need in this railway station, Energyplus software is used to simulate the radiant floor heating system. Building model of the same railway station in Lhasa as described in Section 2.1 is built, as shown in Fig. 5.

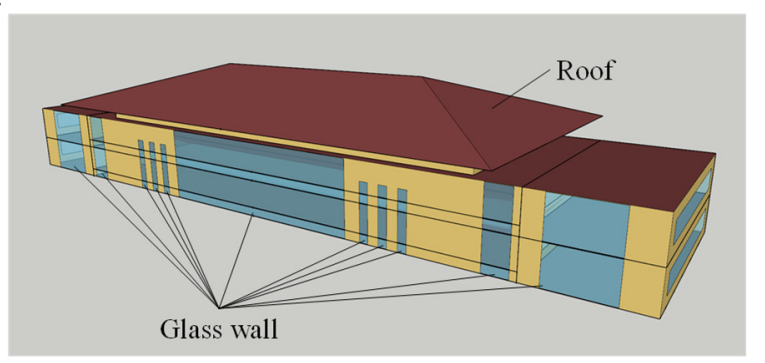

Fig. 5. Energyplus model of the studied railway station.

In the waiting hall of the railway station studied, the low temperature radiant floor system is used for heating. The material of hot water pipe is PE-RT, and the structure of the radiant floor is determined as shown in Fig. 6 and Table $2[7,13]$. Moreover, the tube spacing is $0.3 \mathrm{~m}$ and the internal diameter of pipe is $15 \mathrm{~mm}$ in this system.

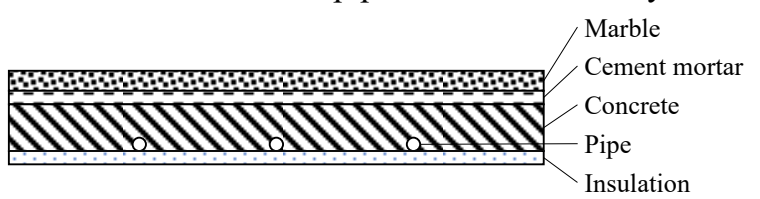

Fig. 6. Structure of the radiant floor.

Table 2. Thermal properties of materials of the radiant floor.

\begin{tabular}{ccccc}
\hline \multirow{2}{*}{ Material } & $\begin{array}{c}\text { Thickness Conductivity Density Specific Heat } \\
(\mathbf{m m})\end{array}$ & $\begin{array}{c}\mathbf{W} / \mathbf{m} \cdot \mathbf{K}) \\
\left(\mathbf{k g} / \mathbf{m}^{\mathbf{3}}\right)\end{array}$ & $(\mathbf{J} / \mathbf{k g} \cdot \mathbf{K})$ \\
\hline Marble & 30 & 3.84 & 2600 & 750 \\
Cement mortar & 20 & 0.93 & 1800 & 840 \\
Concrete & 70 & 1.84 & 2344 & 800 \\
Pipe (PE-RT) & 2.5 & 0.38 & 1200 & 1400 \\
\hline
\end{tabular}

In addition, the supply water temperature of the radiant floor heating system is $50^{\circ} \mathrm{C}$ in this study. This system has a variable flow rate depending on the heating need, and the maximum velocity of hot water inside the pipe is 0.4 $\mathrm{m} / \mathrm{s}$.

For the radiant floor system, the thermal comfort analysis is always based on the operative temperature $\left(T_{o p}\right)$, and the thermal comfort range is $20 \sim 24{ }^{\circ} \mathrm{C}$ in the heating season [14]. In this study, the operative temperature is used to control the heating system. According to the current engineering situation, all coils of the radiant floor system are controlled simultaneously. If this railway station is open (during the operation time 6:00 - 23:00) and the $T_{o p}$ somewhere in the waiting hall is below $20^{\circ} \mathrm{C}$, turn on the radiant floor heating system. Otherwise, the heating system remains off.

\subsection{Heat sources, infiltration and outdoor air}

According to relevant standards, design manuals and a survey [15-17], some heat sources, infiltration and outdoor air in the waiting hall are determined as shown in Table 3. In addition, the operation time of this railway station is 6:00 23:00 normally, and these values change continuously according to the operation time.

Table 3. Thermal disturbances in the waiting hall of the railway station.

\begin{tabular}{ccc}
\hline Thermal disturbance & Calculation method & Value \\
\hline People & Number & 2000 \\
Lights & Watts per area & $10 \mathrm{~W} / \mathrm{m}^{2}$ \\
Electric equipment & Watts per area & $15 \mathrm{~W} / \mathrm{m}^{2}$ \\
Infiltration & Air change per hour & $3.2 \mathrm{hr}^{-1}$ \\
Outdoor air & Flow per person & $10 \mathrm{~m}^{3} / \mathrm{h}$ \\
\hline
\end{tabular}

Finally, in this railway station, there are some rooms next to the waiting hall and these rooms are not the focus of this study. Therefore, the air temperature of them is set at a constant of $18^{\circ} \mathrm{C}$ in the simulation.

\section{Results of simulation}

In this section, the simulation results are presented to analyze the influence of uneven solar radiation distribution on the radiant floor system.

\subsection{Indoor temperatures}

In the simulation, the meteorological parameters in Lhasa are used and the simulated period is also from November 15 to March 15 of the following year. According to the meteorological data, the three sunniest days with the most abundant solar radiation during the heating period are from January 14 to 16 . In these three days, the outdoor air temperature fluctuates between $-10{ }^{\circ} \mathrm{C}$ and $8{ }^{\circ} \mathrm{C}$, and the solar radiation (including direct and diffuse solar radiation) can exceed $800 \mathrm{~W} / \mathrm{m}^{2}$ in the afternoon.

In the waiting hall of this railway station, the largest difference between the $\mathrm{S}$ zone and the $\mathrm{W}$ zone is the solar radiation irradiating on the floor surface. Then, the variations of average solar radiation on the floor surface in each zone from January 14 to 16 are depicted in Fig. 7.

It can be seen from Fig. 7. that the solar radiation on the floor surface has a huge difference between the $\mathrm{S}$ zone and the $\mathrm{W}$ zone. The average solar radiation on the floor surface is usually below $5 \mathrm{~W} / \mathrm{m}^{2}$ in the $\mathrm{W}$ zone, while in the $\mathrm{S}$ zone the maximum value can exceed $50 \mathrm{~W} / \mathrm{m}^{2}$ in the afternoon, which has a great effect on the indoor thermal environment of the waiting hall.

In addition, the indoor thermal environment of the 
waiting hall is analyzed. The variations of floor surface temperature and indoor operative temperature from January 14 to 16 are depicted in Fig. 8. In this study, $T_{s}$ and $T_{o p}$ represent the floor surface temperature and the indoor operative temperature, respectively.

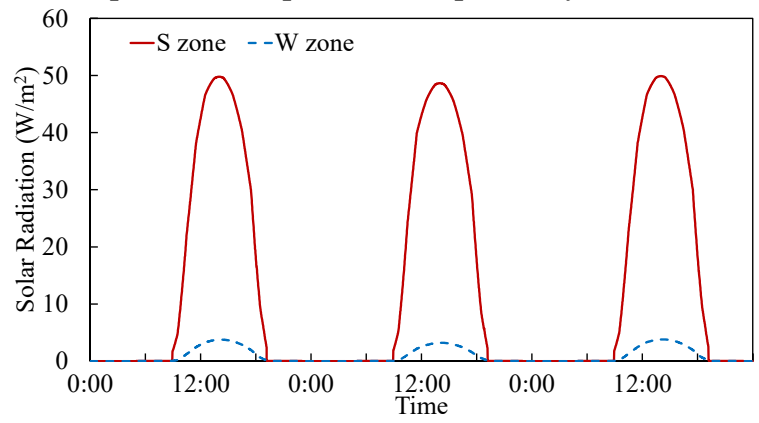

Fig. 7. Average solar radiation on the floor surface from Jan. 14 to 16 .

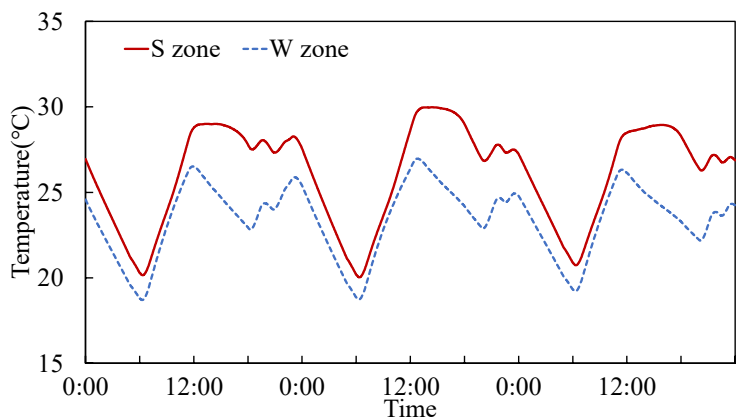

(a) $T_{s}$ from Jan. 14 to 16 .

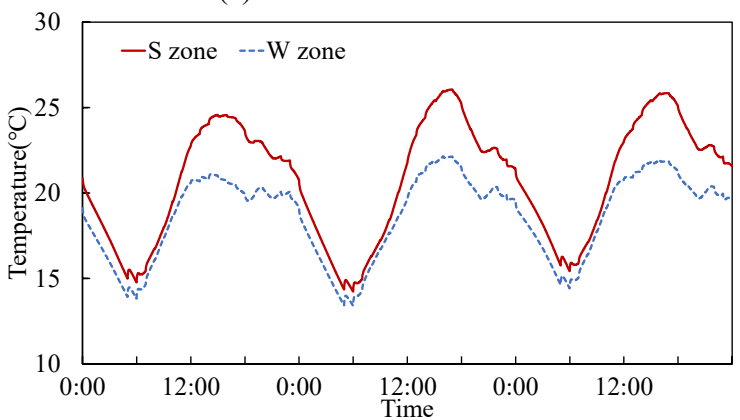

(b) $T_{o p}$ from Jan. 14 to 16 .

Fig. 8. Variations of $T_{s}$ and $T_{o p}$.

In Fig. 8, at night without solar radiation, there are small differences in $T_{s}$ and $T_{o p}$ between the $\mathrm{S}$ zone and the $\mathrm{W}$ zone. However, with the increasing solar radiation during the daytime, the differences are gradually obvious. In the afternoon, $T_{s}$ can reach $30^{\circ} \mathrm{C}$ and $T_{o p}$ can reach $26^{\circ} \mathrm{C}$ in the $\mathrm{S}$ zone because of the solar radiation, forming a temperature differences of nearly $3{ }^{\circ} \mathrm{C}$ and $4{ }^{\circ} \mathrm{C}$ with the $\mathrm{W}$ zone, respectively. During the whole heating season, the temperature difference of $T_{s}$ between the $\mathrm{S}$ zone and the $\mathrm{W}$ zone can be even more than $5^{\circ} \mathrm{C}$ at some moments.

In order to fully understand the differences caused by solar radiation between the $\mathrm{S}$ zone and the $\mathrm{W}$ zone, the temperature range of $T_{s}, T_{o p}$ and their proportion to the total operation time of this railway station in the heating season (a total of 2057 hours) are shown in Table 4. Moreover, the hours about the temperature differences of $T_{s}, T_{o p}$ between the $\mathrm{S}$ zone and the $\mathrm{W}$ zone are shown in
Fig. 9

According to the above results, $T_{s}$ and $T_{o p}$ in the $\mathrm{S}$ zone are significantly higher than those in the $\mathrm{W}$ zone during most time due to the influence of solar radiation. In terms of temperature differences of $T_{s}$ and $T_{o p}$, the number of hours with a temperature difference of more than $1{ }^{\circ} \mathrm{C}$ between the S zone and the $\mathrm{W}$ zone are 1768 and 1473, respectively. Therefore, under the influence of solar radiation, the indoor thermal environment of the waiting hall is significantly decreased.

Table 4. Temperature range and their proportion to the total operation time.

\begin{tabular}{ccccc}
\hline $\begin{array}{c}\text { Temperature range } \\
\left({ }^{\circ} \mathrm{C}\right)\end{array}$ & \multicolumn{2}{c}{$\boldsymbol{T}_{\boldsymbol{s}}$} & \multicolumn{2}{c}{$\boldsymbol{T}_{\boldsymbol{o p}}$} \\
\cline { 2 - 5 } S zone & W zone & S zone & W zone \\
\hline $12 \sim 14$ & $0.0 \%$ & $0.0 \%$ & $0.6 \%$ & $2.0 \%$ \\
$14 \sim 16$ & $0.0 \%$ & $0.0 \%$ & $6.9 \%$ & $8.9 \%$ \\
$16 \sim 18$ & $0.0 \%$ & $0.0 \%$ & $10.0 \%$ & $9.8 \%$ \\
$18 \sim 20$ & $0.9 \%$ & $6.4 \%$ & $9.6 \%$ & $47.2 \%$ \\
$20 \sim 22$ & $8.3 \%$ & $9.0 \%$ & $32.8 \%$ & $31.1 \%$ \\
$22 \sim 24$ & $8.0 \%$ & $43.0 \%$ & $25.8 \%$ & $1.1 \%$ \\
$24 \sim 26$ & $20.7 \%$ & $36.0 \%$ & $14.0 \%$ & $0.0 \%$ \\
$26 \sim 28$ & $40.1 \%$ & $5.6 \%$ & $0.2 \%$ & $0.0 \%$ \\
$28 \sim 30$ & $21.9 \%$ & $0.0 \%$ & $0.0 \%$ & $0.0 \%$ \\
$30 \sim 32$ & $0.1 \%$ & $0.0 \%$ & $0.0 \%$ & $0.0 \%$ \\
\hline
\end{tabular}

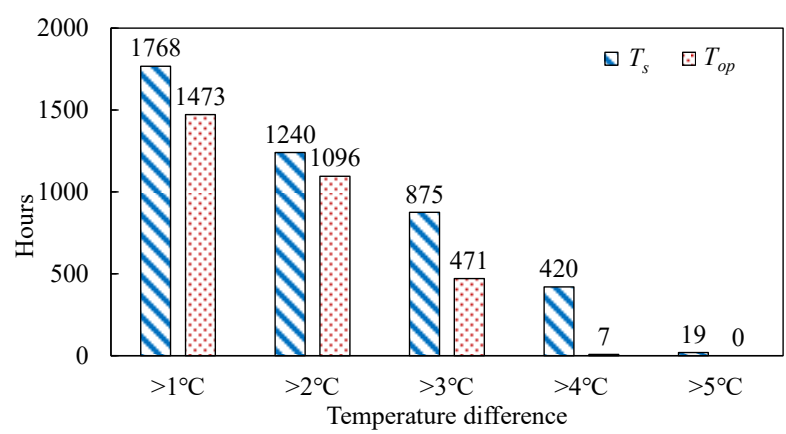

Fig. 9. Hours of temperature differences between the $\mathrm{S}$ zone and the $\mathrm{W}$ zone.

\subsection{Heating needs}

This section will further analyze the heating needs of radiant floor system and the results of the $\mathrm{S}$ zone and the $\mathrm{W}$ zone during the whole heating season are shown in Fig. 10.

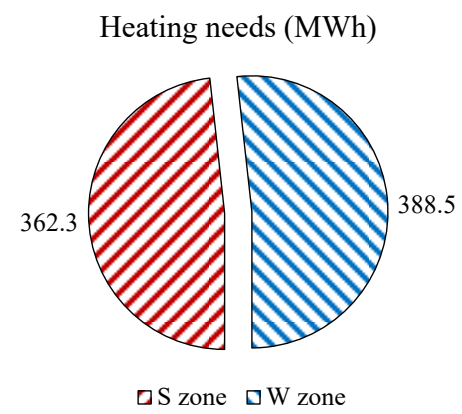

Fig. 10. Heating needs of radiant floor system in the $\mathrm{S}$ zone and the $\mathrm{W}$ zone.

During the whole heating season, the heating need of the radiant floor system in the $\mathrm{S}$ zone is $362.3 \mathrm{MWh}$, while 
the value is $388.5 \mathrm{MWh}$ in the $\mathrm{W}$ zone. Combined with the above simulation results of indoor thermal environment, it can be found that the heat supply in the $S$ zone is excessive. Therefore, the radiant floor heating system in the $\mathrm{S}$ zone still has a large energy saving potential.

\section{Conclusions}

Solar radiation is extremely strong on Tibetan Plateau and it irradiates on part of the radiant floor surface through the transparent envelope of building. This paper studies the influence of uneven solar radiation distribution on the radiant floor heating system through a model of a railway station, and some important conclusions are summarized as follows:

1) In transportation buildings like railway stations on Tibetan Plateau, the solar radiation irradiating on the floor varies greatly in different areas. For the dividing of the $\mathrm{S}$ zone and the $\mathrm{W}$ zone, the solar radiation irradiating on the floor surface in the $\mathrm{W}$ zone during the heating season is only $30.2 \%$ of that in the $\mathrm{S}$ zone.

2) Because of the influence of the solar radiation, both the floor surface temperature and the indoor operative temperature in the $\mathrm{S}$ zone can be $5{ }^{\circ} \mathrm{C}$ and $4{ }^{\circ} \mathrm{C}$ higher than those in the $\mathrm{W}$ zone during the daytime, which largely affects the indoor thermal comfort.

3 ) In the $S$ zone, the large amount of heating need is accompanied by overheating for a long time. Therefore, reducing the heating in the area with strong solar radiation and making full use of solar radiation for heating is an effective way to reduce the heating energy consumption of heating system.

Overall, in transportation buildings on Tibetan Plateau, uneven solar radiation distribution is an important factor affecting the operation of radiant floor heating system. In the future, developing a novel radiant floor heating system based on uneven solar radiation distribution is a promising way to improve the indoor thermal comfort and reduce the heating energy consumption. Moreover, the applicability of this novel system needs to be further studied.

\section{Acknowledgments}

This research work was financially supported by the "National Key R\&D Program of China" (No.2018YFC0705000) and the Sichuan Science and Technology Program (grant No. 19ZDYF0452).

\section{References}

1. THUBERC, 2018 Annual Report on China Building Energy Efficiency. 2018, Beijing.

2. Wang, Q. and H.-N. Qiu, Situation and outlook of solar energy utilization in Tibet, China. Renewable and Sustainable Energy Reviews, 2009. 13(8): p. 2181-2186.

3. Yu, W., et al., A study of thermal comfort in residential buildings on the Tibetan Plateau, China. Building and Environment, 2017. 119: p. 71-86.
4. Ralegaonkar, R.V. and R. Gupta, Review of intelligent building construction: A passive solar architecture approach. Renewable and Sustainable Energy Reviews, 2010. 14(8): p. 2238-2242.

5. Olesen, B.W., Radiant floor heating in theory and practice. Ashrae Journal, 2002. 44(7): p. 19-26.

6. Zhao, K., X.-H. Liu, and Y. Jiang, Application of radiant floor cooling in a large open space building with high-intensity solar radiation. Energy and Buildings, 2013. 66: p. 246-257.

7. Zhao, K., X.-H. Liu, and Y. Jiang, Dynamic performance of water-based radiant floors during start-up and high-intensity solar radiation. Solar Energy, 2014. 101: p. 232-244.

8. Feng, J., S. Schiavon, and F. Bauman, New method for the design of radiant floor cooling systems with solar radiation. Energy and Buildings, 2016. 125: p. 9-18.

9. Athienitis, A.K., Investigation of thermal performance of a passive solar building with floor radiant heating. Solar Energy, 1997. 61(5): p. 337-345.

10. Athienitis, A.K. and Y. Chen, The effect of solar radiation on dynamic thermal performance of floor heating systems. Solar Energy, 2000. 69(3): p. 229237.

11. China, M.o.h.a.u.r.d.o.t.p.s.R.o., Design standard for energy efficiency of public buildings. 2015: Beijing.

12. Zhou, J., et al., A dynamic model of hollow ventilated interior wall integrated with solar air collector. Applied Thermal Engineering, 2020. 175.

13. Zhao, K., X.-H. Liu, and Y. Jiang, On-site measured performance of a radiant floor cooling/heating system in Xi'an Xianyang International Airport. Solar Energy, 2014. 108: p. 274-286.

14. CEN, EN ISO 7730: Ergonomics of the Thermal Environment: Analytical Determination and Interpretation of the Thermal Comfort Using Calculation of the PMV And PPD Indices and Local Thermal Comfort Criteria. 2005, CEN.

15. Qian, B., et al., Measurements of Energy Consumption and Environment Quality of HighSpeed Railway Stations in China. Energies, 2019. 13(1).

16. Lu, Y., Practical heating and air conditioning design manual. 1993, Beijing: China Architecture \& Building Press.

17. China, N.R.A.o.P.s.R.o., Code for Design of Railway Passenger Station. 2018: Beijing. 